\title{
Explaining variation in life-history traits: growth rate, size, and fecundity in a marine snail across an environmental gradient lacking predators
}

\author{
L. Miguel Pardo ${ }^{1,2, *}$, Ladd E. Johnson ${ }^{1}$ \\ ${ }^{1}$ Département de biologie \& Québec-Ocean, Université Laval, Québec, Québec G1K 7P4, Canada \\ ${ }^{2}$ Universidad Austral de Chile, Facultad de Ciencias, Instituto de Biologia Marina 'Jurgen Winter', \\ Independencia 641, Valdivia, Chile
}

\begin{abstract}
Intertidal invertebrates are model organisms for examining the environmental control of life-history traits because of the sharp gradients in biological and physical factors found in their habitat, including wave action, temperature, food availability, and predation. However, the effect of a particular factor on ecological and evolutionary processes is difficult to separate when multiple factors vary simultaneously. We examined shifts in life-history traits in the intertidal gastropod Littorina saxatilis Olivi across an intertidal shoreline where predation appears to have little influence. We determined the density, size, fecundity, and size at maturity of snails in 4 distinct zones across the shoreline and estimated growth rates in each zone. Size, fecundity, median size at maturity, and growth rate all exhibited pronounced clines across the shoreline with higher values in the lower zones, where food abundance was highest. Snail density, however, peaked in the mid-zones. The clines in life-history traits corresponded with food availability and environmental stress (wave forces and desiccation stress), and these factors were the likely determinants of the patterns observed. We also conducted a reciprocal transplant experiment between the extreme zones to assess if any differences in growth rate might have a genetic basis. Snails transplanted from the high zone to the low zone grew 7 times faster than snails that remained in the high zone and, more unexpectedly, 1.6 times greater than local snails from the low zone. Snails transplanted from the low zone to the high zone did not grow at all while local snails from the high zone had slow, although measurable, growth. These divergent responses of transplanted snails (i.e. counter-gradient variation) suggest that there may be differential size-dependent selection between the extreme zones with the greater wave forces of the low shore selecting against fast growth which would otherwise be supported by the abundance of food found there.
\end{abstract}

KEY WORDS: Cline $\cdot$ Counter-gradient variance $\cdot$ Littorina saxatilis $\cdot$ Resource gradient $\cdot$ Rocky intertidal shore Resale or republication not permitted without written consent of the publisher

\section{INTRODUCTION}

Large differences in morphology, size structure, size at maturity, growth, sex ratio, and fecundity have been detected among populations inhabiting different environments (Pigliucci 2001), and determining the bases of the phenotypic differentiation is a fundamental requirement for understanding the evolution of different life histories (Roff 1992, Stearns 1992). Variability in demographic and life-history traits is often attributed to additive genetic variation or phenotypic plasticity in response to selection pressures such as predation (Crowl \& Covich 1990) or the physical environment (Hoffman \& Parsons 1989). For example, differences in size-specific predation among populations can lead to strong variation in individual size and size at maturity (Riessen 1999, Palumbi 2001). Similarly, spatial variation in the effects of a non-lethal stressor 
(e.g. temperature) or resource availability (e.g. food) should lead to different phenotypic responses (Stearns 1992, Chase 1999).

Variability in life-history traits has been extensively studied in both land and aquatic snails (Baur \& Raboud 1988, Johannesson \& Johannesson 1996, Johnson \& Black 1998, Trussell 2000, Negovetic \& Jokela 2001). These animals are particularly well-suited to such studies since their gene flow can be limited - adults move little (Little 1989), and many species have direct development of juveniles (Johannesson 1988, Little 1989, Kyle \& Boulding 2000). In intertidal habitats, snails can exhibit large habitat-dependent phenotypic variability between populations separated by even a few meters (Johannesson 2003). These habitats are often characterized by strong gradients in abiotic and biotic factors, such as predation, food availability, and physical factors (e.g. hydrodynamic forces, desiccation), which ultimately depend on intertidal height or exposure (Underwood 1984, Menge 2000, Addy \& Johnson 2001, Somero 2002). When these factors act differentially (e.g. size-selective predation), they can produce clinal variation in life-history traits, and gradients in such factors have been invoked to explain pronounced vertical clines in size structure and other lifehistory traits (Vermeij 1972, Rochette et al. 2003).

Past studies of marine snails examining life-history traits across intertidal gradients have focussed primarily on the influence of predation and only rarely explored alternative possibilities. In particular, the importance of food resources as a determinant of life-history characteristics has often been overlooked (but see Kemp \& Bertness 1984, Underwood 1984, Takada 1995). However, due to the complexity of natural communities, it is usually difficult to separate the relative influence of different factors on life-history traits. For example, the presence of small individuals in a particular environment might be due to low food availability, high metabolic costs of a stressful environment, selective predation on larger individuals or some combination thereof. Thus, simpler ecological systems may provide a better opportunity to assess the importance of particular factors in determining observed variation in life-history traits.

In addition, variability may be due to additive genetic variation, phenotypic plasticity, and environmental constraints. An efficient means of distinguishing among these possibilities is the use of common garden and reciprocal transplant experiments to separate genetic and environmental effects on phenotype (Conover \& Schultz 1995). This approach has allowed researchers to assess the degree of interaction between genotype and environment in phenotypic expression of a variety of animals including clams (Jokela \& Mutikainen 1995), lizards (Niewiarowski \& Roosenburg 1993) and fish (Hendry et al. 2002).
In this study, we assess the demographic and lifehistory traits of the ovoviviparous snail Littorina saxatilis across an intertidal environment where predation appears very rare. This 'predator-free' system permits us to examine how variation in other environmental factors influences life-history traits. Specifically, we documented changes in demography (density and size-structure) and life-history traits (average size, growth rates, fecundity, size at maturity) across 4 intertidal zones as well as conducted a reciprocal transplant experiment between the highest and lowest zones to determine if our observed differences in life-history traits were due strictly to environmental conditions. Our results suggest that these traits are directly affected by food availability and indirectly by selection for slower growth in resource-rich habitats.

\section{MATERIALS AND METHODS}

The study was conducted in the intertidal zone at Pointe-Mitis $\left(48^{\circ} 41^{\prime} \mathrm{N}, 67^{\circ} 02^{\prime} \mathrm{W}\right)$, located on the southern shore of the St. Lawrence maritime estuary, Québec, Canada. This site has an extensive rocky shore of long rock ridges running parallel to the shoreline, interspersed with tide pools or boulders set in a matrix of mud or mussels (Mytilus spp.). Littorinid snails are common across most of the intertidal zone which can be divided into 4 different habitats across the shore: (1) a low zone, where rock ridges are covered with a green algal mat in spring and early summer (except near crevices used by the snails as refuges from wave action; Addy \& Johnson 2001, Pardo 2004). The mat is composed primarily of the filamentous green algae Urospora penicilliformis (Roth) Aresch. and Ulothrix flacca (Dillwyn) Thur. which gradually disappear toward the end of July; (2) a lower-mid zone consisting of a matrix of bare rock surfaces, fucoid canopies (Fucus spp. and Ascophyllum nodosum [L.] Le Jol.), and green algal mats; (3) an upper-mid zone which is similar to the lowermid zone but without green algal mats; and (4) a high zone of bare rock surfaces without any macroalgae. These 4 zones are consistently found at this site, regardless of the slope of the shoreline. Littorina saxatilis is the most common snail on rock ridges, where perennial algae are less common due to the annual effect of ice scour. It is present in all zones whereas its congener L. obtusata was less abundant and is found primarily on the canopy of fucoid algae. A larger species, L. littorea, is uncommon at the site and is generally found only in habitats more protected from waves. All sampling and experiments were conducted exclusively on the rock ridges and not in boulder areas, where fucoid algae are more abundant. 
Demography and life-history traits. Demographic and life-history traits were examined for 3 transects that extended across the intertidal zone to include all 4 above-mentioned zones. Transects were selected randomly within a $1 \mathrm{~km}$ stretch of shoreline in May and June 2002. The length of each transect depended on the shore slope and was $80 \mathrm{~m}$ for Transect $1,30 \mathrm{~m}$ for Transect 2 and $45 \mathrm{~m}$ for Transect 3 . Tidal heights (m) for the mid-point of each zone were $0.5,1.2,2.3,3.3$ (Transect 1), 0.7, 1.6, 2.0, 2.5 (Transect 2), and 0.3, 1.2, 1.7, 2.1 (Transect 3). Ten quadrats of $0.25 \mathrm{~m}^{2}$ were selected in each zone by throwing the quadrat haphazardly within a $3 \times 20 \mathrm{~m}^{2}$ area centered in the zone. Each quadrat was photographed, and then counts of snails were made. In quadrats containing fucoid algae, care was taken to distinguish Littorina saxatilis from $L$. obtusata. The photographs were used to estimate percent cover of bare rock, green algal mats, and fucoid algae (the percent cover of green algal mats was considered to be a proxy for food availability). When mussels were present, their cover was also estimated but was not included in the analysis as they were not abundant and represent a much less suitable habitat for these snails.

For 3 randomly selected quadrats, snails were also collected to determine size (shell length) frequency, sex, and reproductive condition. If more than 110 snails were found in the quadrat, 100 were randomly selected for determining size frequency and 40 to 50 for sex and reproduction condition (individuals were dissected to examine reproductive structures and then categorised as immature females, immature males, adult non-gravid females, gravid females, or adult males; Reid 1989). Snails with trematode infestations $(<4 \%)$ were not used in the analyses because of the effects of parasitism on growth and reproductive structures (Lafferty 1993). For gravid females, embryos were also counted, and fecundity estimated as the number of embryos $\mathrm{mg}^{-1}$ ash-free dry weight (AFDW) of soft tissue, not including the weight of embryos. AFDW was estimated from the regression between shell length of females in $\mathrm{mm}$ (SL) and AFDW in $\mathrm{mg}$. Because slopes of regressions were non-homogeneous among zones $\left(F_{3,147}=9.62 ; \mathrm{p}<0.001\right)$, separate regressions were calculated for each zone (low zone: $\mathrm{AFDW}=0.07 \mathrm{SL}^{2.26}, \mathrm{r}=0.97, \mathrm{~N}=45$; lower-mid zone: $\mathrm{AFDW}=0.03 \mathrm{SL}^{2.61}, \mathrm{r}=0.96, \mathrm{~N}=41$; upper-mid zone: $\mathrm{AFDW}=0.02 \mathrm{SL}^{2.79}, \mathrm{r}=0.82, \mathrm{~N}=38$; and high zone: $\mathrm{AFDW}=0.02 \mathrm{SL}^{3.48}, \mathrm{r}=0.98, \mathrm{~N}=31$ ).

Full factorial design ANOVAs were used to determine differences in size (shell length), density, relative fecundity among transects, zones and sexes (only for the analysis of shell length). Transect was used as a random factor whereas zone and sex were treated as fixed factors. Densities and sizes were natural log- transformed to meet the assumption of homogeneity of variance, which was tested with Cochran's test. After ANOVAs, post-hoc comparisons (Student-NewmanKeuls test) were used to assess differences between different zones. As a positive relationship between the size of females and their relative (mass-specific) fecundity was found, size was used as a covariate to determine the effect of zone on relative fecundity.

A logistic regression for the dichotomous response between size and maturity condition was used to determine the size of sexual maturity for each sex in each zone in each transect. An inverse prediction function was used to estimate the size at which $50 \%$ of individuals were mature (Rochette et al. 2003). To examine the effects of transect, zone, sex, and size, and their interactions on the size at maturity, a multiple logistic regression was performed using the CATMOD procedure in the SAS statistical package (Stokes et al. 1995). Triple interactions were not included as they did not improve the model (low likelihood ratio).

An estimate of the production of embryos in each zone (embryos $\mathrm{m}^{-2} \mathrm{yr}^{-1}$ ) was calculated using mean values of density, sex ratio, size at maturity, proportion of gravid females, and mean of number of embryos per female for each zone in each transect. As Littorina saxatilis is probably multivoltine (gravid females are found from at least April until December), this calculation provides only a minimal estimate of production.

Growth. To determine growth rates, 200 snails were collected from each zone in May, were tagged in the laboratory, were returned to the field within $10 \mathrm{~h}$ and then were collected 4 mo later. Snails were selected to have good representation of different sizes above a shell length of $3 \mathrm{~mm}$, the smallest size that can be efficiently tagged. All snails were identified with small ( $2 \mathrm{~mm}$ diameter) numbered plastic bee tags (The Bee Works), and the external surface of the superior lip of the opercular opening was marked using a Mark$\mathrm{Tex}^{\mathrm{TM}}$ pen to visualize new shell formation (i.e. new shell material lacks the mark). To assess possible genetic influences on growth rate, 200 snails from the extreme ends of the gradient (the low and high zones) were collected, marked, and then reciprocally transplanted to the other zone. After $4 \mathrm{mo}$, marked snails were recovered, measured to determine growth (linear increase of the shell margin) and dissected to determine sex and reproductive condition. ANCOVAs were used to determine differences in the net growth rate and relative fecundity among snails in different zones and from different origins. Initial size was used as a covariate, and Scheffé test was used for post-hoc comparisons.

Predation. Tethering experiments, a technique commonly used to evaluate predation rates in gastropods and crustaceans (Fernandez et al. 1993, Boulding 1999, 
Rochette \& Dill 2000), were used to assess levels of predation on littorinids. Experimental units consisted of tethering snails to an $80 \mathrm{~cm}$ long piece of monofilament line anchored to the rock at each end. Four large $(\geq 6 \mathrm{~mm})$ and 4 small $(<4 \mathrm{~mm})$ snails were attached in a random order to this line at $10 \mathrm{~cm}$ intervals using monofilament tethers $5 \mathrm{~cm}$ in length. Tethers were attached to the shell using fast-drying cyanoacrylic glue. The experiment began in early summer of 2003 at 3 intertidal levels (low, middle, high; 6 replicates in each zone) that corresponded approximately to the transitions between the 4 zones described above. Survival was assessed after 1 wk, 1 mo and 3 mo. To distinguish mortality due to predation from shell damage caused by abrasion against the rock surface (snails often become detached from the rock surface), each dead snail was dissected to determine if there was a substantial loss of soft body tissue.

\section{RESULTS}

\section{Demography and life-history traits}

Snail size was negatively correlated with tidal height, i.e. individuals in lower zones were larger (Fig. 1). This gradient was generally seen in all transects even though there were substantial differences in size within a given zone among the different transects. No difference in size was detected between sexes (Table 1).

The density of snails varied substantially among transects and zones (Table 1), and even between adjacent zones in the same transect, e.g. mean densities (SD) of $2076 \mathrm{~m}^{-2}$ (604) and $95 \mathrm{~m}^{-2}$ (46) were recorded in the upper-mid and high zones, respectively, of the first transect. Despite this large variation, the density of snails generally increased from the low to the upper-mid zone but then fell in the high zone (Fig. 2a). Overall, the mean density of snails for each zone was negatively correlated with the mean size of snails $\left(\mathrm{r}^{2}=0.43 ; \mathrm{n}=12\right)$.

Size was a good predictor of mass-specific fecundity (Table 1), and the relationship did not differ among zones (i.e. no significant Size $\times$ Zone interaction). Fecundity was similar among transects but differed significantly among zones with females in the lower

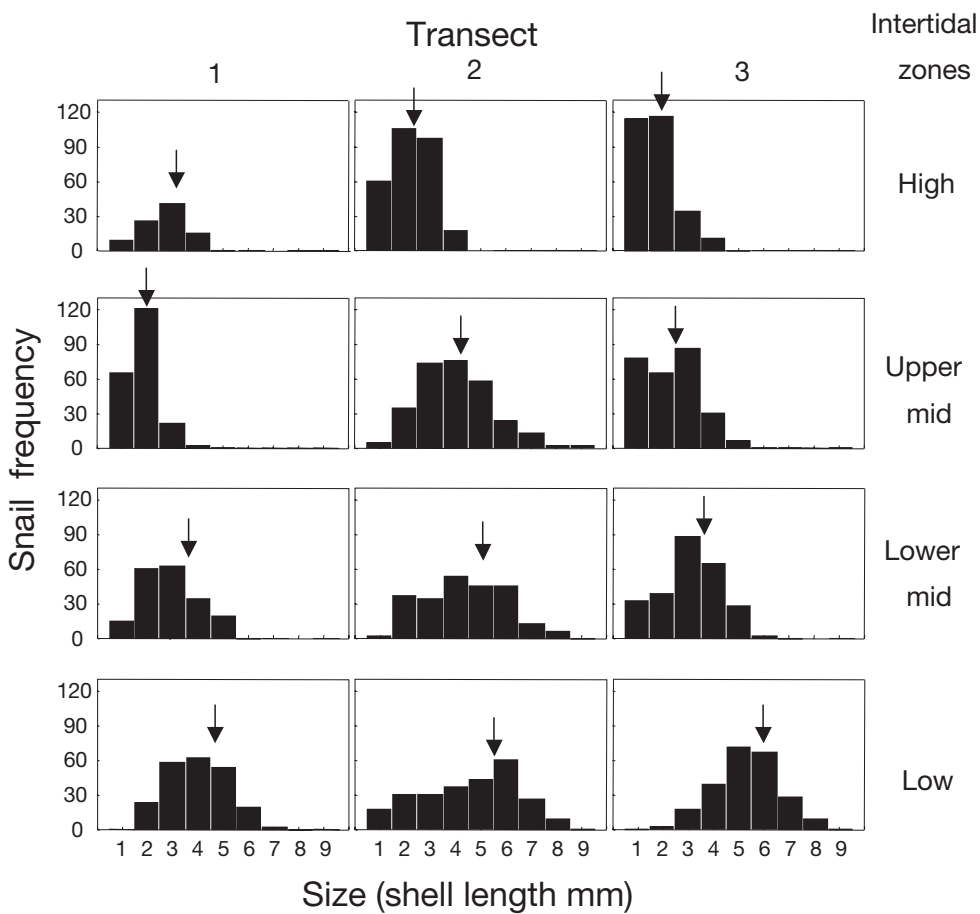

Fig. 1. Littorina saxatilis. Frequency of shell length in 4 intertidal zones along 3 transects. Snails pooled from three $0.25 \mathrm{~m}^{2}$ quadrats for each zone in each transect (data do not represent densities as only a maximum of 110 snails were measured from each quadrat). Arrows indicate mean size

Table 1. ANOVAs and ANCOVA for differences in life-history traits and density of the snail Littorina saxatilis collected in different transects and zones

\begin{tabular}{|c|c|c|c|c|c|}
\hline $\begin{array}{l}\text { Dependent } \\
\text { variable }\end{array}$ & Source of variation & df & MS & $F$ & $\mathrm{p}$ \\
\hline Shell & Transect & 2 & 2.94 & 112 & $<0.001$ \\
\hline \multirow{7}{*}{$\begin{array}{l}\text { length } \\
(\mathrm{mm})\end{array}$} & Zone & 3 & 12.65 & 5.65 & 0.03 \\
\hline & Sex & 1 & 0.03 & 0.54 & 0.54 \\
\hline & Transect $\times$ Zone & 6 & 2.24 & 85.69 & $<0.001$ \\
\hline & Transect $\times$ Sex & 2 & 0.05 & 2.04 & 0.21 \\
\hline & Zone $\times$ Sex & 3 & 0.02 & 0.86 & 0.51 \\
\hline & Transect $\times$ Zone $\times$ Sex & 6 & 0.03 & 0.33 & 0.92 \\
\hline & Error & 1249 & 0.08 & & \\
\hline \multirow{4}{*}{$\begin{array}{l}\text { (ind. } \mathrm{m}^{-2} \text { ) } \\
\text { (ind }\end{array}$} & Transect & 2 & 14.17 & 0.91 & 0.45 \\
\hline & Zone & 3 & 9.61 & 0.61 & 0.63 \\
\hline & Transect $\times$ Zone & 6 & 15.63 & 25.04 & $<0.001$ \\
\hline & Error & 108 & 0.62 & & \\
\hline Relative & Size (cov) & 1 & 2.34 & 14.7 & $<0.001$ \\
\hline fecundity & Transect & 2 & 0.15 & 0.64 & 0.56 \\
\hline (embryos/ & Zone & 3 & 1.81 & 8.11 & 0.01 \\
\hline AFDW & Transect $\times$ Zone & 6 & 0.23 & 1.42 & 0.21 \\
\hline female) & Error & 294 & 0.16 & & \\
\hline
\end{tabular}

zone carrying more embryos than females of the same size in higher zones (Fig. 2b, Table 1).

The multiple logistic regression analysis indicated that size (i.e. shell length) was a strong predictor of maturity (Table 2). Snails matured at a larger size in lower zones although there was no difference between the upper-mid and the high zone (Table 2, Fig. 2c). 
Maturity was also affected by sex with males maturing at a smaller size in all zones (e.g. females were nearly $25 \%$ larger at maturity than males in the low zone) although this difference was less pronounced in higher zones (Table 2, Fig. 2c).

Estimated production of embryos was maximal in the lower-mid zone (17000 embryos $\mathrm{m}^{-2}$ ) and minimal in the high zone (300 embryos $\mathrm{m}^{-2}$; Fig. 3 ), a >50-fold difference. Eighty percent of the reproductive output at this site was thus produced by the $35 \%$ of the population residing in the 2 lowest zones.

A gradient in the primary source of food of Littorina saxatilis was seen with decreasing abundance of green algal mats with increasing tidal height (Fig. 4). The mats were most abundant in the lowest zone but were completely absent from the 2 highest zones. In contrast, fucoid algae were found in all zones but were most abundant in the 2 mid zones.
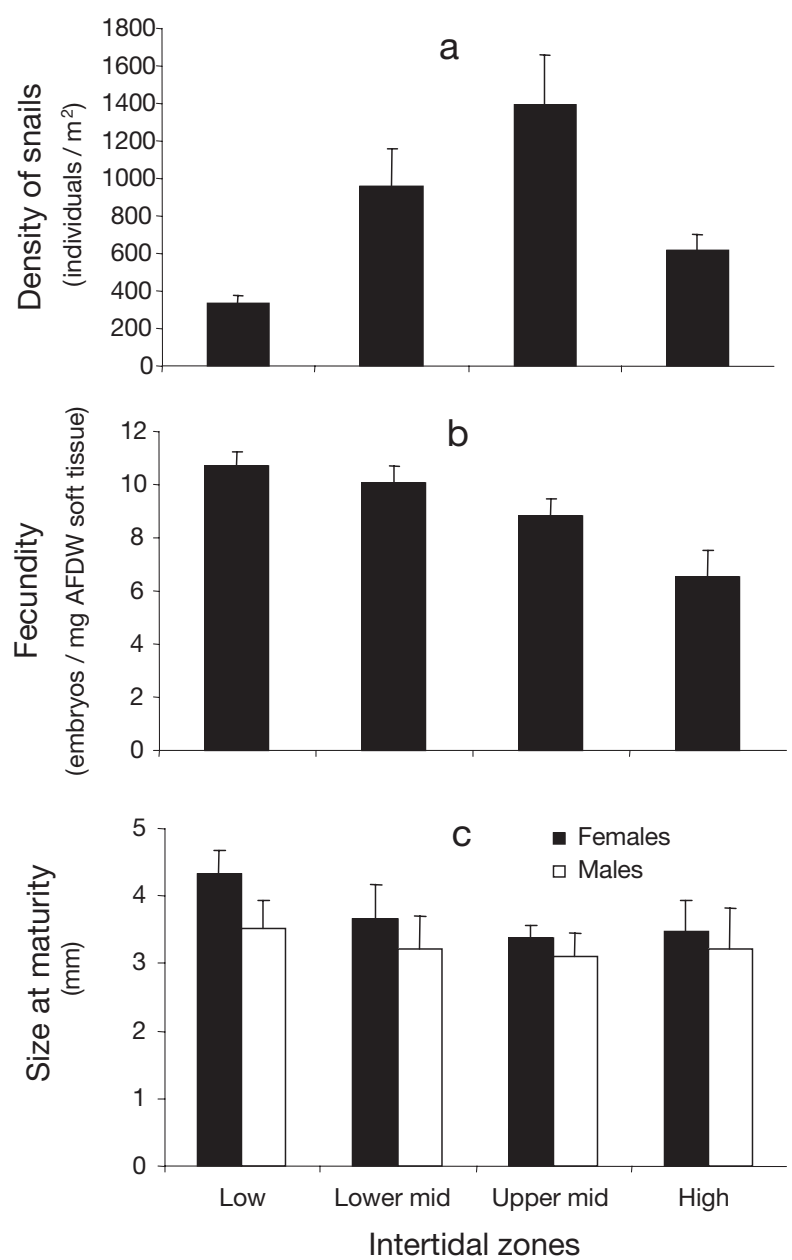

Fig. 2. Littorina saxatilis. Demographic and life-history characteristics in different intertidal zones: (a) density; (b) relative fecundity; (c) median size at maturity. Data from 3 transects were pooled. Bars represent standard errors
Table 2. Analysis of maximum likelihood estimates of logistic regression on the maturity condition of individual Littorina saxatilis

\begin{tabular}{|lccc|}
\hline Source of variation & df & Wald $\chi^{2}$ & $\mathrm{p}$ \\
\hline Size & 7 & 168 & $<0.001$ \\
Sex & 1 & 7.5 & 0.006 \\
Transect & 2 & 4.57 & 0.1 \\
Zone & 9 & 25.8 & $<0.001$ \\
Size $\times$ Sex & 7 & 10.9 & 0.14 \\
Size $\times$ Transect & 14 & 17.6 & 0.23 \\
Size $\times$ Zone & 63 & 82.6 & 0.049 \\
Sex $\times$ Zone & 2 & 0.3 & 0.85 \\
Maximum likelihood ratio & & & 0.999 \\
\hline
\end{tabular}

\section{Growth}

Overall, $25 \%$ of marked individuals were recaptured after $4 \mathrm{mo}$, with some variation among the zones: 25, 30,17 , and $28 \%$ in order of increasing intertidal height. For transplanted snails the percentages of recapture were $27 \%$ for the high-zone snails transplanted to the low zone, but only $3 \%$ for the low-zone snails transplanted to the high-zone. The low recapture rate for this last group (reflecting higher mortality and/or dispersal) adds greater uncertainty to our conclusions but we include them regardless given their distinct response (no growth). This treatment was, however, excluded from the statistical analysis as their inclusion violated certain assumptions. Snails were never recovered in any zone other than the one in which they were released.

A pronounced vertical cline in growth rate was seen across the shore with snails from the low zone growing over 4 times faster than snails from the high zone (Table 3, Fig. 5). Significant differences were always seen between adjacent zones. Females grew approxi-

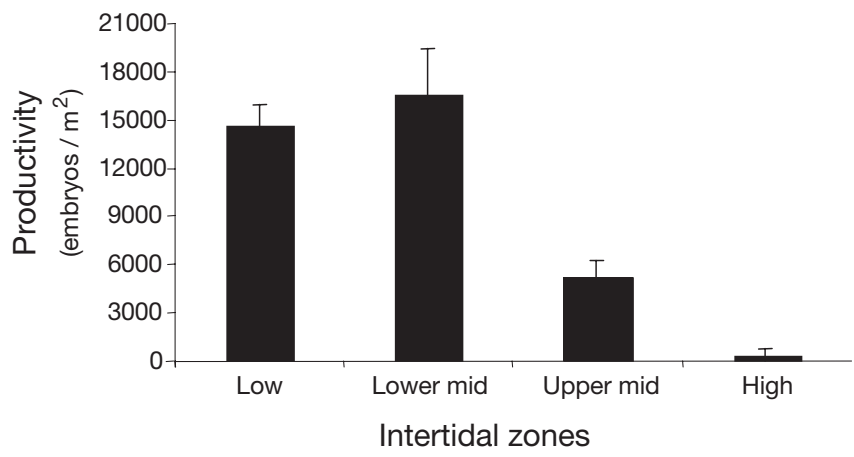

Fig. 3. Littorina saxatilis. Production of embryos in different intertidal zones; values were calculated for each quadrat $(\mathrm{n}=$ 30 for each zone) using the individual quadrat density and the overall sex ratio, female size at maturity, and fecundity estimated from 3 quadrats in each zone of each of the 3 transects. Bars represent standard errors 


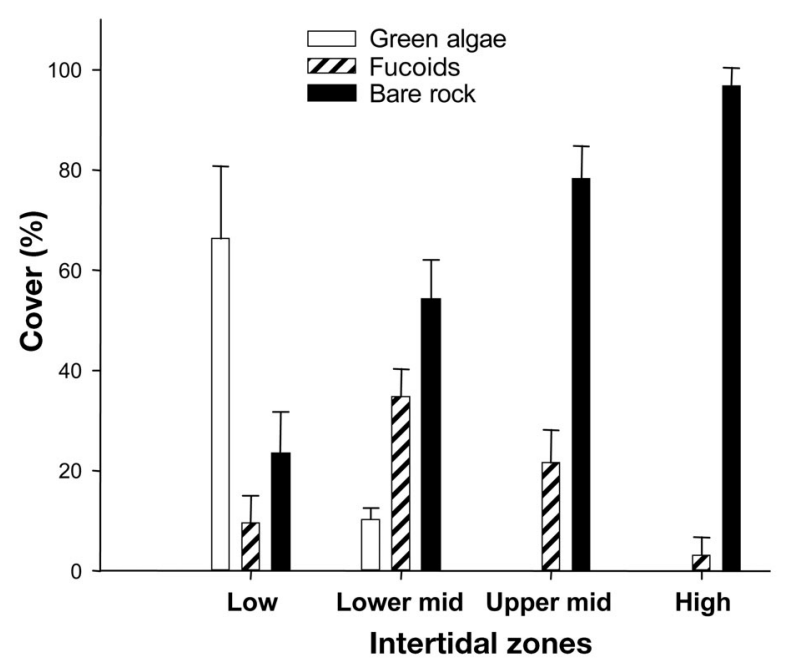

Fig. 4. Abundance of green algal mat, fucoid algae and bare rock in 4 intertidal zones. Means and standard errors for 30 quadrats pooled from 3 transects. Area covered by mussels (typically $<10 \%$ ) was not used in calculating percent covers of algae and bare rock

mately $30 \%$ faster than males, but the clines in growth rate were similar for both sexes.

Transplanted snails exhibited the extremes in growth rates. Snails originating from the high-zone and transplanted to the low zone ('high-to-low') grew 7 times faster than source controls (high-zone snails that were returned to the high zone) and almost 1.6fold greater than destination controls (low-zone snails that were returned to the low zone) (Fig. 5). In contrast, the low-zone snails transplanted to the high zone ('low-to-high') did not grow at all. Growth rate was thus influenced by both the immediate local environment (faster in the low zone) as well as the past origin of the snails (faster for snails from the high zone). A significant interaction was detected between the factor Zone and the covariate Size (Table 3). A visual inspection of slopes of the relationship between initial size and growth for the different treatments revealed that this interaction was due mostly to differences between

Table 3. ANCOVA for sex differences in shell growth for Littorina saxatilis living in 4 different intertidal zones. Size was used as covariate in the analysis

\begin{tabular}{|lcccc|}
\hline Source of variation & df & MS & $F$ & $p$ \\
\hline Intertidal zone & 4 & 12.3 & 60.0 & $<0.001$ \\
Sex & 1 & 1.59 & 7.8 & 0.006 \\
Size $($ covariate) & 1 & 6.89 & 33.7 & $<0.001$ \\
Zone $\times$ Sex & 4 & 0.17 & 0.8 & 0.5 \\
Zone $\times$ Size & 4 & 0.63 & 3.08 & 0.017 \\
Sex $\times$ Size & 1 & 0.21 & 1.0 & 0.3 \\
Zone $\times$ Sex $\times$ Size & 4 & 0.14 & 0.7 & 0.6 \\
Error & 232 & 0.20 & & \\
\hline
\end{tabular}

high-to-low transplanted snails and the local low-zone snails (Fig. 6). In this case, growth rates were significantly different only for sizes under $6.7 \mathrm{~mm}(F=3.86$, $\mathrm{N}_{1}=48, \mathrm{~N}_{2}=54, \mathrm{p}=0.05$; Johnson-Neir technique; Huitema 1980).

Females exhibited large differences in fecundity, relative to body mass, between low and high zones with females of the low zones having 2 to 3 times more embryos (Fig. 7). Although trends between growth rate and fecundity were similar among zones, there was no significant correlation between growth rate and relative fecundity for individual snails $\left(\mathrm{r}^{2}=0.1, \mathrm{p}=0.09\right.$, $\mathrm{n}=150$ ). Regardless of their origin, fecundity of transplanted snails differed markedly from their respective source control groups but did not differ from their respective destination control groups (Fig. 7). In other words, unlike growth rates, fecundity appeared to depend strictly on the local environment. The difference between transplanted and local snails in the high zone was, however, considerable (1.9 vs. 3.3 embryos $\mathrm{mg}^{-1}$ AFDW female tissue, respectively), and the lack of a statistical difference in this case (Scheffé test; $\mathrm{p}=$ 0.2 ) may be more related to the low number of transplanted snails recaptured there.

\section{Predation}

Mortality in the tethering experiment was very low (typically 10 to $20 \%$, Fig. 8) and was not significantly

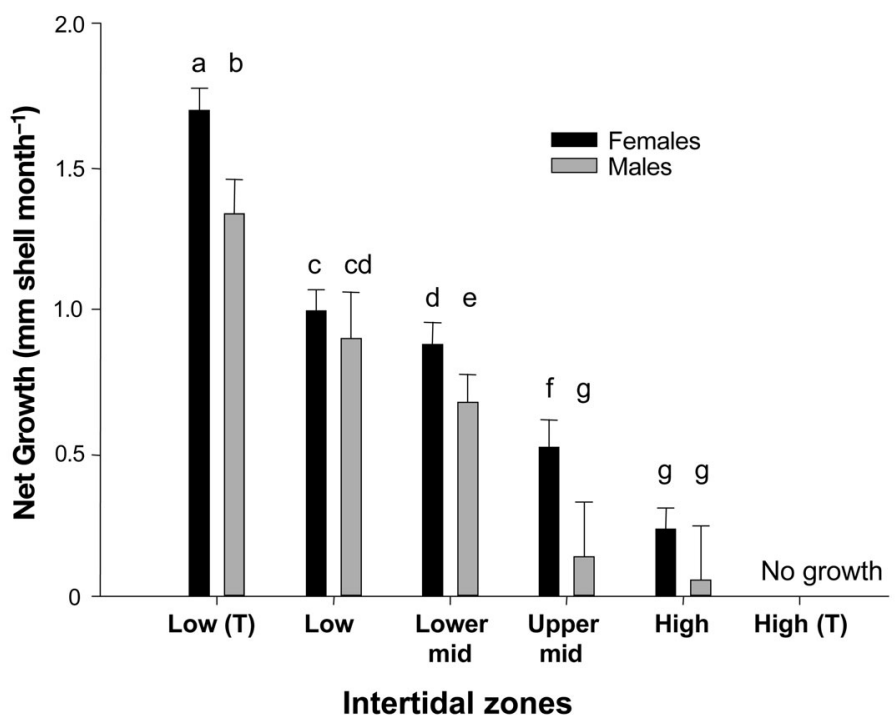

Fig. 5. Littorina saxatilis. Mean growth rate (linear increase in shell formation) for males and females, determined from marked individuals from different intertidal zones. Low (T) represents snails transplanted from the high zone to low zone and High $(\mathrm{T})$ represents the reciprocal transplant. Different letters represent statistical differences (SNK multiplecomparison, $\mathrm{p}<0.05)$. Bars represent standard errors 


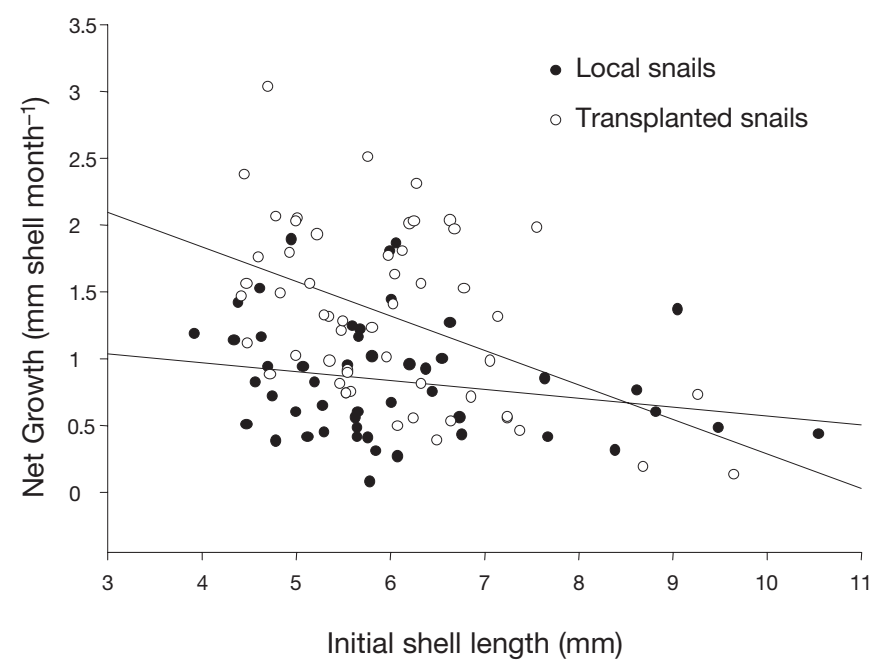

Fig. 6. Littorina saxatilis. Growth rate (linear increase in shell formation) for individual snails transplanted from the high zone to the low zone and for local snails in the low zone. Lines represent linear regressions for each group

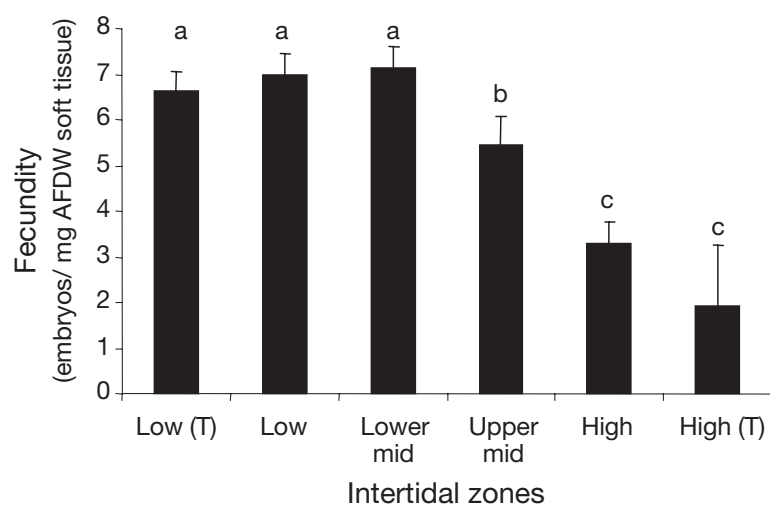

Fig. 7. Littorina saxatilis. Fecundity of local and transplanted female from low and high intertidal zones. Low (T) represents snails transplanted from the high zone to the low zone and High (T) represents the reciprocal transplant. Different letters represent statistical differences (SNK multiple-comparison, $\mathrm{p}<0.05)$. Bars represent standard errors

different among intertidal zones after $1 \mathrm{wk}$ and $1 \mathrm{mo}$ (week: $F_{2,30(\text { level) }}=0.3, \mathrm{p}=0.7, F_{1,30 \text { (size) }}=1.5, \mathrm{p}=0.2$, $F_{2,30 \text { (interaction) }}=0.6, \mathrm{p}=0.5$; month: $F_{2,30 \text { (level) }}=2.7, \mathrm{p}=$ $0.08, F_{1,30 \text { (size) }}=1.2, \mathrm{p}=0.3, F_{2,30(\text { interaction })}=0.03, \mathrm{p}=0.9$ ). After $3 \mathrm{mo}$, differences were found in levels $\left(F_{2,30}=5.3\right.$, $\mathrm{p}=0.01$ ) with mortality highest in the lowest zone (Fig. 8). No significant differences were seen for size or the interaction between zone and size $\left(F_{1,30}=0.9, \mathrm{p}=\right.$ $0.3, F_{2,30}=0.5, \mathrm{p}=0.6$, respectively). All dead snails had broken shells, but there was no indication that this was due to predators (i.e. the shell appeared abraded and the soft body tissue was largely intact) and most, if not all, of the observed mortality was likely artefactual, i.e. due to the tethering itself.

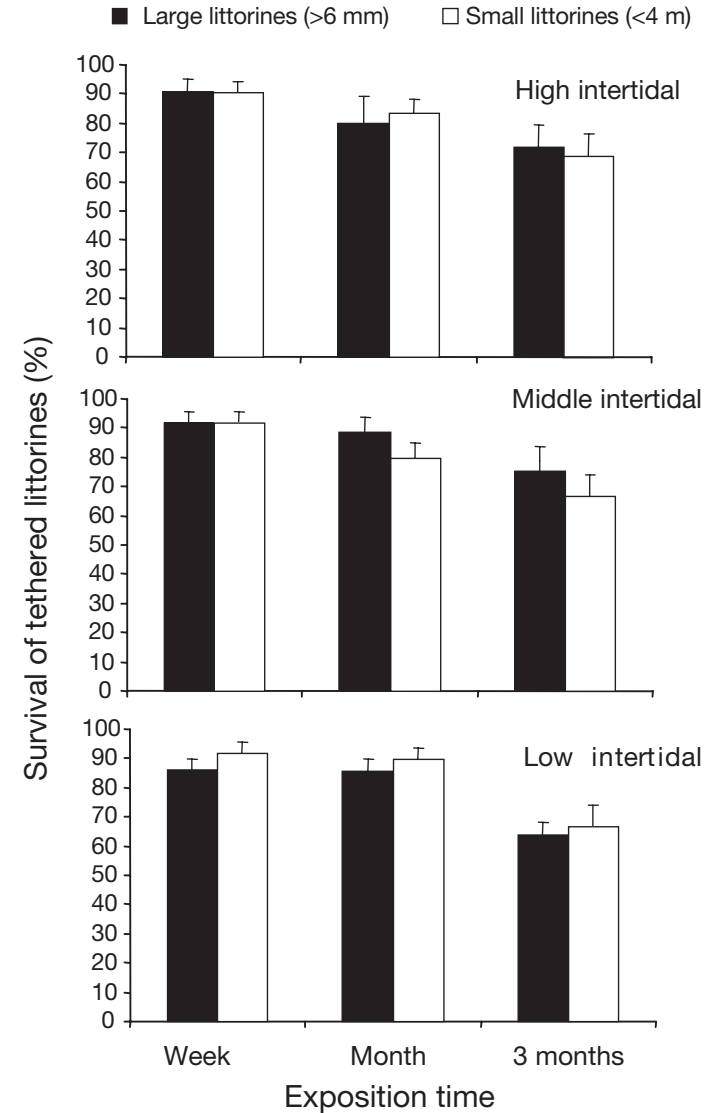

Fig. 8. Littorina saxatilis. Relative mortality of 2 size categories (small and large) tethered at 3 levels (low, mid, and high) in the intertidal zone over 3 time periods $(1 \mathrm{wk}, 1 \mathrm{mo}$ and $3 \mathrm{mo}$ ). Bars represent standard errors

\section{DISCUSSION}

Variation in life-history traits among different habitats has been observed in a number of other studies contrasting different populations of littorinid snails, including those comparing sheltered and exposed shores (e.g. Janson 1982, Boulding \& Van Alstyne 1993, Trussell 2002) and different shore heights (e.g. Berry 1961, Vermeij 1972, McQuaid 1981, Johannesson et al. 1997). The mechanisms proposed to explain these differences vary widely and include differences in growth rate (e.g. Underwood 1984, Takada 1995, Johannesson et al. 1997), survival (e.g. Rochette et al. 2003), or migration (e.g. McQuaid 1981, McCormack 1982, Rochette et al. 2003). In contrast to these earlier studies, we found the opposite pattern of size variation across different shore heights with the largest snails inhabiting lower zones on the shore (but see also McQuaid 1981).

Theory predicts that life-history variation should be intrinsically tied to differences in the characteristics of 
different habitats (Roff 1992, Stearns 1992), and crossshore differences in the demographics or traits of intertidal snails have been attributed to clinal variation in the environment (Vermeij 1972). For littorinid snails, variation in predation has been suggested as one of principal factors creating life-history differences among individuals in different environments (Boulding 1999, Rochette \& Dill 2000, Johannesson 2003, Rochette et al. 2003). Predation pressure generally varies across the shore, though not always predictably (Johannesson 2003), and its effect on snail populations will depend on both spatial variation of predation intensity (e.g. high vs. low intertidal zones) and variability in the vulnerability of individuals with different attributes (e.g. size, shell thickness). However, at our study site, predation rates appear extremely low as the tethering experiment revealed no evidence of predation, even though such experiments normally overestimate mortality rates (Aronson et al. 2001). This low predation rate is likely due to very low density of certain predators (fish and crabs; L. M. Pardo pers. obs.) or the abundance of alternative prey for others (e.g. mussels for eider ducks; Guillemette 1998). Thus, predation does not appear to play an important role in creating the differences we observed among different habitats.

Although this situation may be somewhat atypical, it does allow us to examine more closely others factors that modify life-history traits without the confounding influence of predation. The most likely explanation for the observed gradient in size is the difference in growth rate across this intertidal gradient with larger snails found in zones in which growth rates were higher. Growth rate, however, can depend on a number of extrinsic and intrinsic factors, including the abundance of food, access to food (e.g. foraging time), energetic costs, and genetics. Food (i.e. algal mats and benthic microalgae) is certainly more abundant lower on the shore due to lower desiccation and lower grazing pressure. Our results are consistent with previous studies in which food availability has been given as the most parsimonious explanation for the gradients of growth rate across intertidal habitats (Underwood 1984, Takada 1995). Thus, a gradient in size opposite to that seen in other situations (i.e. size decreasing with increasing tidal height rather than increasing) could be produced in the absence of predation by a gradient in growth rate, ultimately controlled by food availability as determined by primary production and grazing pressure (Etter 1996, Tenhumberg et al. 2000). Moreover, faster growth does not appear to be at the expense of reproductive output as mass-specific fecundity showed the same pattern: highest in the low zone and gradually decreasing with tidal height. Thus, performance, based on either growth rate or fecundity, was clearly greater in lower zones with greater growth rates producing larger individuals and greater fecundity.

Without experimental manipulation of the food resources (e.g. Kemp \& Bertness 1984), we cannot, however, be certain how important food availability might be relative to other explanations. Energetic costs are also likely to vary in a parallel manner across the shoreline with individuals living in higher zones experiencing a greater degree of thermal and osmotic stress and thus incurring greater energetic costs (e.g. anaerobiosis, replacement of denatured proteins; Somero 2002). Such costs would reduce resources available for growth and reproduction.

Differences in growth rate and fecundity among the different groups of snails could also have a genetic basis, a possibility suggested by our transplant experiment. Snails transplanted to the low zone grew faster than local snails while for those transplanted to the high zone, local snails grew faster than the transplanted ones, i.e. snails from the high shore appear to have inherently higher growth rates regardless of the environment. While this difference may be due to underlying genetic differences, it could also be caused by other factors, including environmentally induced characteristics (e.g. metabolic rates, behaviour) developed within the local environment prior to transplantation. For example, snails from the high shore may be more opportunistic since the wet conditions favourable to snail foraging in high intertidal habitats are more limited and more unpredictable (Zann 1973, Norton et al. 1990, Chapman 2000). If so, then once transplanted to a lower zone, where foraging conditions are less limited, their foraging efforts could exceed those of the local snails leading to greater energetic gains but also a greater risk of dislodgment (Addy \& Johnson 2001). In contrast, given the low recovery rate of snails transplanted to the high zone, they must have either suffered higher mortality (perhaps from lack of food or physiological stress) or dispersed more widely, possibly migrating to lower shore levels.

While we cannot preclude these possible causes, a substantial genetic component to the variation in growth rate across the intertidal zone would not be surprising given the strong selective gradient and the limited dispersal of this species. Indeed, genetic differences have been observed in Littorina saxatilis elsewhere over similar short distances (Wilding et al. 2001, Johannesson 2003). If both genetic and environmental effects were occurring, one should assess how the two are interacting. In our case, the direction of environmental effects would be opposed to the genetic predisposition of the snails, i.e. snails living in the food-rich environment of the lower zones had lower potential growth rates. This type of response to a variable envi- 
ronment, known as counter-gradient variation (Conover \& Schultz 1995, Trussell 2002) occurs when the influence of selection on a given trait acts in the opposite direction as environmental conditions. It is operationally detected when there is a divergence in the response of reciprocally transplanted individuals such as we observed in our study. In our case, selection pressure appears to favour snails with higher growth rates in the high zones and acts against snails with higher growth rates in low zones. The selective agents at this site are most likely related to clines in the physical environment across the shore (Garrity 1984, Addy \& Johnson 2001, Somero 2002). In particular, wave forces should be selecting for smaller size in the lower zones, not only if size and adhesion strength vary allometrically (Denny et al. 1985), but also because larger snails may have a reduced ability to fit into the topographic irregularities (e.g. holes, crevices) used as shelter from hydrodynamic forces (Boulding \& Van Alstyne 1993, Trussell 1997, 2002, Pardo \& Johnson 2004). In addition, there is greater thermal and desiccation stress in higher intertidal zones, and smaller snails have been shown to be more susceptible to desiccation than larger ones (Jones \& Boulding 1999). Thus, selection may favour genotypes with low growth potential in lower zones and those with high growth potential in higher zones. The environment would then be operating in 2 contrasting manners, first, by creating a gradient in the resource base, and, second, by acting as the selective agent working against the organism's exploitation of the resource.

Whereas the above explanation can account for differences in the size of snails across this environmental gradient, there is no obvious explanation for the changes in densities of snails among the different zones or transects. The negative correlation between density and mean size suggests that resource competition may play a role, but it is difficult to reconcile why snail density should peak in the upper mid-zone. Lower densities in the high zone are likely due to resource limitations and the physical severity of this extreme environment. The lower densities in the 2 lowest zones are unexpected given the high level of food resources available there, but may represent limitations in shelters. Moreover, reproductive rates are higher in the lower zones with the larger size and higher fecundity of individuals more than compensating for the lower densities of these zones. Production of juveniles in the 2 lowest zones exceeded adult densities by 15 to 40 times, and given that this species reproduces by direct development with brooded juvenile snails released by females, there must be either high levels of mortality or emigration occurring in these zones. The source of any such mortality remains unclear. Dispersal could also be occurring, and popula- tions of higher zones might be demographically supported by dislodgment and transport of juveniles and adults upshore by waves (Magalhães 1998). Such passive dispersal would rapidly obliterate any genetic divergence between populations, and if the differences in growth rates that we observed do have a genetic basis, the differences would be occurring within a single generation and are therefore of primarily ecological relevance.

Interestingly, regardless of the habitat or treatment, growth rates of females always exceeded that of males although this difference did not lead to size differences, suggesting that mortality might be higher for females. Greater growth rates in females have been described for other members of the Littorinidae (e.g. Rochette et al. 2003) and are not surprising given the exponential relationship between fecundity and size in invertebrates (Ramirez Llodra 2002) which provides disproportionally more benefits to larger females. This allometric relationship is particularly advantageous for brooding species, for which an increment in size could represent a large increment in brood capacity.

We have shown here that demographic and lifehistory traits of this intertidal snail can vary dramatically across a short, yet strong environmental gradient in the intertidal zone. Variation in snail size was the opposite of that seen in earlier studies of littorinid snails due to an apparent absence of predation in this system which allowed resource availability to assume a primary role. Beyond the direct influence of resource availability on growth rate, selection also appeared to play a role in this system as animals from different environments responded differently when placed in a common environment. Counter-intuitively, selective pressure by the physical environment (i.e. dislodgment by hydrodynamic forces) may be working against the influence of resource availability by selecting for individuals with lower growth rates (and thus smaller sizes) in zones of high food availability. As always, one must be careful not to extrapolate these results beyond the domain of the study. Although the transects were located along a kilometer of shoreline, our transplant experiment was limited to a single site, and additional laboratory and field experiments (including translocation controls; Chapman 1986) should be done as well as studies to examine the snail's genetic structure at this location. Thus, it remains to be seen if the natural and experimental patterns that we observed are common elsewhere, and certainly other factors in other times and places could lead to different patterns and different conclusions. Still, this study provides a strikingly different example of the environmental control of population structure in this ubiquitous group of marine herbivores and illustrates the need for integrating both observational and experimental approaches. 
Acknowledgements. We appreciate the financial support of an NSERC Discovery Grant (170178; L.E.J.), a team research grant from FCAR (E. Bourget et al.), and student stipends from Laval University (Fonds soutien des étudiants) and Québec-Océan (formerly GIROQ, Groupe interuniversitaire de recherches océanographiques du Québec). We also thank J. Dodson and G. Houle for intellectual input and J. Himmelman and the anonymous reviewers for their critical reading of an earlier version of this paper. Finally, we thank J. Breton and C. Vallières for assistance in the field. All experimental work was conducted in Canada and complied with its existing laws.

\section{LITERATURE CITED}

Addy TC, Johnson LE (2001) Littorine behavior and population structure on a wave-exposed shore: non-linear response across a physical gradient. J Shell Res 20: 385-391

Aronson RB, Heck KL, Valentine JF (2001) Measuring predation with tethering experiments. Mar Ecol Prog Ser 214: 311-312

Baur B, Raboud C (1988) Life history of the land snail Arianta arbustorum along an altitudinal gradient. J Anim Ecol 57: 71-87

Berry AJ (1961) Some factors affecting the distribution of Littorina saxtilis (Olivi). J Anim Ecol 30:27-45

Boulding EG (1999) Regulation of wave-sheltered Littorina sitkana populations by pile perch, Rhacochilus vacca. J Shell Res 18:688

Boulding EG, Van Alstyne KL (1993) Mechanisms of differential survival and growth of two species of Littorina on wave-exposed and on protected shores. J Exp Mar Biol Ecol 169:139-166

Chapman MG (1986) Assessment of some controls in experimental transplants of intertidal gastropods. J Exp Mar Biol Ecol 103:1-3

Chapman MG (2000) Variability of foraging in high shore habitats: dealing with unpredictability. Hydrobiologia 426:75-87

Chase JM (1999) To grow or to reproduce? The role of lifehistory plasticity in food web dynamics. Am Nat 154: 571-586

Conover DO, Schultz ET (1995) Phenotypic similarity and the evolutionary significance of countergradient variation. Trends Ecol Evol 10:248-252

Crowl TA, Covich AP (1990) Predator-induced life-history shifts in a freshwater snail. Science 247:949-951

Denny MW, Daniel TL, Koehl MAR (1985) Mechanical limits to size in wave-swept organisms. Ecol Monogr 55:69-102

Etter RJ (1996) The effect of wave action, prey type, and foraging time on growth of the predatory snail Nucella lapillus (L.). J Exp Mar Biol Ecol 196:341-356

Fernandez M, Armstrong D, Iribarne O (1993) First cohort of young-of-the-year Dungeness crab, Cancer magister, reduces abundance of subsequent cohorts in intertidal shell habitat. J Can Fish Aquat Sci 50:2100-2105

Garrity SD (1984) Some adaptation of gastropods to physical stress on a tropical rocky shore. Ecology 65:559-574

Guillemette M (1998) The effect of time and digestion constraints in common eiders while feeding and diving over blue mussel beds. Funct Ecol 12:123-131

Hendry AP, Taylor E, McPhail J (2002) Adaptive divergence and the balance between selection and gene flow: lake and stream stickleback in the Misty system. Evolution 56: $1199-1216$
Hoffman AA, Parsons PA (1989) An integrated approach to environmental stress tolerance and life-history variation: desiccation tolerance in Drosophila. Biol J Linn Soc 37: $117-136$

Huitema BE (1980) The analyses of covariance and alternatives. John Wiley, New York

Janson K (1982) Genetic and environmental effects on the growth rate of Littorina saxatilis. Mar Biol 69:73-78

Johannesson B, Johannesson K (1996) Population differences in behavior and morphology in the snail Littorina saxatilis: phenotypic plasticity or genetic differentiation? J Zool 240: 475-493

Johannesson K (1988) The paradox of Rockall: why is a brooding gastropod (Littorina saxatilis) more widespread than one having a planktonic larval dispersal stage (L. littorae)? Mar Biol 99:507-513

Johannesson K (2003) Evolution in Littorina: ecology matters. J Sea Res 49:107-117

Johannesson K, Rolan-Alvarez E, Erlandsson J (1997) Growth rate differences between upper and lower shore ecotypes of the marine snail Littorina saxatilis (Olivi) (Gastropoda). Biol J Linn Soc 61:267-279

Johnson MS, Black R (1998) Effects of habitat on growth and shape of contrasting phenotypes of Bembicium vittatum Phillipi in the Houtman Abrolhos Islands, western Australia. Hydrobiologia 378:95-103

Jokela J, Mutikainen P (1995) Phenotype plasticity and priority rules for energy allocation in a freshwater clam: a field experiment. Oecologia 104:122-132

Jones KM, Boulding EG (1999) State-dependent habitat selection by an intertidal snail: the costs of selecting a physically stressful microhabitat. J Exp Mar Biol Ecol 242: 149-177

Kemp P, Bertness MD (1984) Snail shape and growth rates: evidence for plastic shell allometry in Littorina littorea. Proc Natl Acad Sci USA 81:811-813

Kyle CJ, Boulding EG (2000) Comparative population genetic structure of marine gastropods (Littorina spp.) with and without pelagic larval dispersal. Mar Biol 137:5-6

Lafferty KD (1993) Effects of parasitic castration on growth, reproduction and population dynamics of the marine snail Cerithidea californica. Mar Ecol Prog Ser 93:229-237

Little C (1989) Factors governing patterns of foraging activity in littoral marine herbivorous molluscs. J Moll Stud 55: 273-284

Magalhães CA (1998) Density and shell-size variation of Nodilittorina lineolata (Orbigny 1840) in the intertidal region in southeastern Brazil. Hydrobiologia 378:143-148

McCormack SD (1982) The maintenance of shore-level size gradients in an intertidal snail (Littorina sitkana). Oecologia 54:117-183

McQuaid CD (1981) The establishment and maintenance of vertical size gradients in populations of Littorina africana knysnaensis (Philippi) on an exposed rocky shore. J Exp Mar Ecol 54:77-89

Menge BA (2000) Recruitment vs. postrecruitment processes as determinants of barnacle population abundance. Ecol Monogr 70:265-288

Negovetic S, Jokela J (2001) Life-history variation, phenotypic plasticity, and subpopulation structure in a freshwater snail. Ecology 82:2805-2815

Niewiarowski PH, Roosenburg W (1993) Reciprocal transplant reveals source of variation in growth rates of the lizard Sceloporus undulatus. Ecology 74:1992-2002

Norton TA, Hawkins SJ, Manley NL, Williams GA, Watson DC (1990) Scraping a living: a review of littorinid grazing. Hydrobiologia 193:117-138 
Palumbi SR (2001) The evolution explosion. WW Norton, New York

Pardo LM (2004) Sources de variabilité dans les caractéristiques biologiques chez le gastéropode Littorina saxatilis., PhD thesis, Université Laval, Québec

Pardo LM, Johnson LE (2004) Activity and shelter use of an intertidal snail: effects of sex, reproductive condition and tidal cycle. J Exp Mar Biol Ecol 301:175-191

Pigliucci M (2001) Phenotypic plasticity: beyond nature and nurture. The Johns Hopkins University Press, Baltimore, MD

Ramirez Llodra E (2002) Fecundity and life-history strategies in marine invertebrates. Adv Mar Biol 43:87-170

Reid DG (1989) The comparative morphology, phylogeny and evolution of the gastropod family Littorinidae. Phil Trans R Soc Lond B 324:1-110

Riessen HP (1999) Predator-induced life history shifts in Daphnia: a synthesis of studies using meta-analysis. Can J Fish Aquat Sci 56:2487-2494

Rochette R, Dill LM (2000) Mortality, behavior and the effects of predators on the intertidal distribution of littorinid gastropods. J Exp Mar Biol Ecol 253:165-191

Rochette R, Dunmall K, Dill LM (2003) The effect of lifehistory variation on the population size structure of a rocky intertidal snail (Littorina sitkana). J Sea Res 49: 119-132

Roff DA (1992) The evolution of life histories. Chapman \& Hall, London

Somero GN (2002) Thermal physiology and vertical zonation of intertidal animals: optima, limits, and cost of living. Integ and Comp Biol 42:780-789

Editorial responsibility: Otto Kinne (Editor-in-Chief), Oldendorf/Luhe, Germany
Stearns SC (1992) The evolution of life history. Oxford University Press, New York

Stokes ME, Davis CS, Koch GG (1995) Categorical Data analysis using the SAS system SAS Institute, Cary, NC

Takada Y (1995) Variation of growth rate with tidal level in the gastropod Monodonta labio on a boulder shore. Mar Ecol Prog Ser 117:103-110

Tenhumberg B, Tyre AJ, Roittberg B (2000) Stochastic variation in food availability influences weight and age at maturity. J Theor Biol 2002:257-272

Trussell GC (1997) Phenotypic selection in an intertidal snail: effects of a catastrophic storm. Mar Ecol Prog Ser 151:73-79

Trussell GC (2000) Phenotypic clines, plasticity, and morphological trade-offs in an intertidal snail. Evolution 54: 151-166

Trussell GC (2002) Evidence of countergradient variation in the growth of an intertidal snail in response to water velocity. Mar Ecol Prog Ser 243:123-131

Underwood AJ (1984) Microalgal food and the growth of the intertidal gastropods Nerita atramentosa Reeve and Bembicium nanum (Lamarck) at four heights on a shore. J Exp Mar Biol Ecol 79:277-291

Vermeij GJ (1972) Intraspecific shore-level size gradients in intertidal molluscs. Ecology 53:693-700

Wilding CS, Grahame J, Mill PJ (2001) Correlation of morphological diversity with molecular marker diversity in the rough periwinkle Littorina saxatilis (Olivi). J Shell Res 20: 501-508.

Zann LP (1973) Relationships between intertidal zonation and circatidal rhythmicity in littoral gastropods. Mar Biol 18: $243-250$

Submitted: September 15, 2004; Accepted: January 3, 2005 Proofs received from author(s): June 17, 2005 